\title{
Effects of Maternal and Posthatch Dietary Oils and Vitamin E on Antioxidant Capability and Muscle Quality of the Progeny Broilers
}

\author{
Shengying $\mathrm{An}^{1}$, Guanzhong Liu ${ }^{1}$, Yuming Guo ${ }^{2}$ and Qiujuan $\mathrm{Sun}^{2}$ \\ ${ }^{1}$ College of Traditional Chinese Veterinary Medicine, Agricultural University of Hebei, Dingzhou, 073000, P. R. China \\ ${ }^{2}$ The State Key Laboratory of Animal Nutrition, College of Animal Science \& Technology, \\ China Agricultural University, Beijing 100193, P. R. China
}

\begin{abstract}
Effects of maternal and posthatch dietary oils and vitamin E (VE) on antioxidant capability and muscle quality of the progeny broilers were studied. Two-factor experiment was designed, there were two main effects, one was oil source, the other was VE level, diets were as follows: corn oil (CO) $+20 \mathrm{mg} / \mathrm{Kg} \mathrm{VE}$, fish oil (FO) $+20 \mathrm{mg} / \mathrm{Kg} \mathrm{VE}$, $\mathrm{CO}+100 \mathrm{mg} / \mathrm{Kg} \mathrm{VE}$ and $\mathrm{FO}+100 \mathrm{mg} / \mathrm{Kg} \mathrm{VE}$. The results showed that: (1) FO in maternal and posthatch diets significantly reduced body weight of the progeny broilers at $42 \mathrm{~d}(P<0.05)$, significantly increased food/gain ratio $(P$ $<0.01)$ of $0-42 \mathrm{~d}$, significantly increased lipid peroxides malondialdehyde (MDA) content of broiler serums at $10 \mathrm{~d}(P$ $<0.01), 21 \mathrm{~d}(P<0.01), 28 \mathrm{~d}(P<0.01)$ and $42 \mathrm{~d}(P<0.01)$ respectively, there was also a substantial interaction $(P<$ 0.05 ) between oil sources and vitamin levels at $28 \mathrm{~d}$, and also a trend at $42 \mathrm{~d}$, the highest MDA content of serums was always observed in FO with $20 \mathrm{mg} / \mathrm{kg}$ VE group, the lowest MDA content of serums was occured in CO with 100 $\mathrm{mg} / \mathrm{kg}$ VE group. (2) FO inclusion in maternal and posthatch diet increased breast meat MDA content, decreased superoxide dismutase (SOD) activity of breast meat compared to corn oil treatment. (3) Addition of higher level of VE in maternal and posthatch diets significantly reduced MDA content of broiler serums at $10 \mathrm{~d}, 21 \mathrm{~d}(P<0.05), 28 \mathrm{~d}$ $(P<0.05)$ and $42 \mathrm{~d}(P<0.05)$ respectively. (4) Higher level of VE in maternal and posthatch diets also significantly reduced drip loss of breast meat of the progeny broilers, but increased meat MDA significantly, decreased meat SOD activity significantly, besides, there was an interaction trend $(P=0.06)$ between oil source and VE level on meat MDA, FO group with higher VE appeared the highest MDA content in breast meast. These findings suggest that diet with FO need more antioxidant to protect from oxidation, but FO oil with higher VE in maternal and posthatch diets may bring about meat deterioration to the progeny broilers.
\end{abstract}

Key words: breeder, corn oil, fish oil, progeny, vitamin E

J. Poult. Sci., 49: 191-195, 2012

\section{Introduction}

In recent year, maternal effect of dam nutrition on the progeny has received considerable attention, specific ingredients and nutrients fed to hens will influence progeny growth, carcass attributes, enzyme functions, and immunity (Kidd, 2003). Studies indicated that vitamin E (VE) in breeder hen diet affected VE concentration in egg yolk and blood plasma of breeder pullet (Lin et al., 2005), enhanced antioxidant status of offspring chicks (Surai, 2000; Lin et al., 2005), which hint that maternal dietary VE is beneficial to protect the progeny from oxidative stress.

Received: September 23, 2011, Accepted: February 17, 2012

Released Online Advance Publication: March 25, 2012

Correspondence: Prof. Y. Guo, College of Animal Science and Technology, China Agricultural University, No. 2 Yuanmingyuan West Road. Haidian District, Beijing 100193, P.R. China.

(E-mail: guoyum@cau.edu.cn)
N-3 polyunsaturated fatty acid (PUFA) is welcome because of its beneficial effects on cardiovascular health (Siddiqui et al., 2008), immunity (Wang et al., 2000) and inflammatory diseases (Kremer, 2000). Fish oil rich in n-3 PUFA plays different immune function to corn oil, a source of n-6 PUFAs (He et al., 2007), increases the content of n-3 fatty acids in poultry meat especially eicosapentaenoic acid (EPA, C20:5n-3) and docosahexaenoic acid (DHA,C22:6n3) (Hulan et al., 1988; Yang et al., 2010). There are some studies of the two oils on broilers, but there is little information of the additive effects of the two oils in maternal and posthatch broiler diets on the progeny broilers. N-3 PUFA is highly susceptible to peroxidation (Meydani, 1991; Oarada et al., 2008), dietary supplementation with n-3 PUFAs increases the levels of n-3 PUFAs, enhances the production of lipid peroxides (Song et al., 2000), and needs protection of antioxidant such as VE, which may alleviate oxidant stress and optimize immune responses in poultry (Cherian, 2003), 
so the experiment was designed, the objective of the present study was to investigate the different additive effects of maternal and posthatch dietary oil sources and VE level on antioxidant capability, carcass and muscle quality traits of the progeny broilers.

\section{Materials and Methods}

\subsection{Experimental Birds and Diets}

2304 fertile eggs (576 per group) were collected from breeder hens fed diets containing corn oil $(\mathrm{CO})+20 \mathrm{mg} / \mathrm{kg}$ $\mathrm{VE}$, fish oil $(\mathrm{FO})+20 \mathrm{mg} / \mathrm{kg} \mathrm{VE}, \mathrm{CO}+100 \mathrm{mg} / \mathrm{kg} \mathrm{VE}$ and $\mathrm{FO}+100 \mathrm{mg} / \mathrm{kg} \mathrm{VE}$, dietary oil inclusion level in breeder was $2 \%$. These eggs were incubated at $37.6{ }^{\circ} \mathrm{C}$ and $61 \%$ relative humidity in a commercial incubator (EIXD2, QingDao, China) with automatic egg turning. After 21 days incubation, 60 male broilers from each group breeders were divided into 6 replicates of 10 birds each feeding diets containing $\mathrm{CO}+20 \mathrm{mg} / \mathrm{kg} \mathrm{VE}, \mathrm{FO}+20 \mathrm{mg} / \mathrm{kg} \mathrm{VE}, \mathrm{CO}+$ $100 \mathrm{mg} / \mathrm{kg} \mathrm{VE}$ and $\mathrm{FO}+100 \mathrm{mg} / \mathrm{kg} \mathrm{VE}$, dietary oil inclusion level in the progeny was $4 \%$. The basal diet composition was same. The breeder hen diets refer to An et al. (2010), the progeny diets are shown in Table 1, basal diets for starter period (0 to 3 week), grower period ( 4 to 6 week) were formulated to meet Feeding Standards of Chickens (Ministry of Agriculture of P. R.China, 2004). Feed and water were provided ad libitum throughout the experimental period. Other management was conducted according to the recommended guideline for the breeders and broilers.

\subsection{Sample Collection and Analysis}

\subsubsection{Growth Performance of the Progeny Broilers}

At $21 \mathrm{~d}$ and $42 \mathrm{~d}$ of age, chickens of each replicate cage were weighed after $12 \mathrm{~h}$ feed deprivation, and the remaining feed was weighed. Performance indexes such as body weight $(\mathrm{BW})$ gain, feed intake, and ratio of feed to gain were determined.

\subsubsection{Antioxidant Capability of the Progeny Broilers}

malondialdehyde (MDA) and activity of superoxide dismutase (SOD) of serum were detected to measure antioxidant capability of the progeny broilers. At $10 \mathrm{~d}, 21 \mathrm{~d}, 42 \mathrm{~d}$ of age, 6 healthy chickens ( 1 per replicate) were randomly chosen from each treatment, blood samples were collected from the wing vein and centrifuged at $3,000 \mathrm{~g}$ for $10 \mathrm{~min}$ at $4^{\circ} \mathrm{C}$, then the serums were stored at $-30^{\circ} \mathrm{C}$ until assay. Lipid peroxidation of serum was determined by thiobarbituric acid reactive substances (TBARS) expressed as MDA equivalents. SOD activity was assessed by xanthine oxydase and hypoxanthine system, one unit of SOD activity is defined as the amount of enzyme exhibiting 50\% dismutation of the superoxide radical. MDA content and SOD activities were determined using commercial kits supplied by Nanjing Jiancheng Bioengineering Institute (China)

\subsubsection{Carcass Composition and Muscle Quality Traits of the Progeny Broilers}

At $42 \mathrm{~d}$, birds were slaughtered after $12 \mathrm{~h}$ feed deprivation to test the carcass composition and meat quality. Abdominal fat, left thigh and left pectoral muscle were removed and weighed, all the indexes were expressed as percentage of $42 \mathrm{~d}$ live broiler BW before slaughter.

To judge muscle quality, $\mathrm{pH}$ value, drip loss, MDA content and SOD activity of pectoral muscle were detected. The methods were as follows: $\mathrm{pH}$ value of the breast pectoralis major was measured with a portable $\mathrm{pH}$ meter for two times, and expressed as the average value. Regarding drip loss of muscle, about $30 \mathrm{~g}$ of muscle from the same part with same surface area of the pectoralis major was taken and placed in a plastic bag with air, hanging from a hook, stored at $4^{\circ} \mathrm{C}$ for $24 \mathrm{~h}$, then calculate the percentage of the loss weight to the initial muscle weight. MDA Content, SOD activity and protein concentration of pectoral muscle were detected according to reagent kits (Nanjing Jiancheng Bioengineering In-

Table 1. Composition and nutrient level of the progeny diets

\begin{tabular}{lrr|lrr}
\hline \hline \multicolumn{1}{c|}{ Ingredients (\%) } & 0-3 week & 4-6 week & Calculated nutrient & 0-3 week & $4-6$ week \\
\hline Corn & 51.61 & 58.17 & ME (Mcal/kg) & 2.95 & 3.05 \\
Soybean meal & 38.57 & 34.35 & Crude protein (\%) & 21.00 & 19.50 \\
Corn oil & 4.00 & 4.07 & Lysine (\%) & 1.15 & 1.01 \\
Dicalcium phosphate & 1.85 & 1.19 & Calcium (\%) & 1.00 & 0.95 \\
Zeolite & 1.70 & 0.00 & Available P (\%) & 0.45 & 0.35 \\
Limestone & 1.21 & 1.49 & & \\
Salt & 0.35 & 0.30 & & \\
DL-methionine & 0.25 & 0.08 & & \\
Choline chloride $(50 \%)$ & 0.16 & 0.10 & & \\
Lysine-HCL & 0.05 & 0.00 & & \\
Antioxidants & 0.03 & 0.03 & & \\
Vitamin premix & & 0.02 & 0.02 & & \\
Mineral premix & & 0.20 & 0.20 & & \\
Total & 100.00 & 100.00 & & \\
\hline
\end{tabular}

${ }^{1}$ Vitamin premix for broilers provided per kg of diet: vitamin A, $12500 \mathrm{IU}$; vitamin D3, $2500 \mathrm{IU}$; vitamin K3, $2.65 \mathrm{mg}$; vitamin B1, $2 \mathrm{mg}$; vitamin B2, $6 \mathrm{mg}$; vitamin B12, $0.025 \mathrm{mg}$; biotin, $0.0325 \mathrm{mg}$; folic acid 1.25 $\mathrm{mg}$; pantothenic acid $12 \mathrm{mg}$; niacin $50 \mathrm{mg}$.

${ }^{2}$ Mineral premix for broilers provided per kg of diet: $\mathrm{Cu}, 8 \mathrm{mg}$; Zn, $75 \mathrm{mg}$; Fe, $80 \mathrm{mg}$; Mn, $100 \mathrm{mg}$; Se, 0.15 $\mathrm{mg} ; \mathrm{I}, 0.35 \mathrm{mg}$. 
stitute, China), MDA content was measured by TBARS, SOD activity was assessed by xanthine oxydase and hypoxanthine system, protein was assayed by Coomassie brilliant blue method. MDA content of pectoral muscle meat was expressed as nmol / mgprot, meat SOD activity was expressed as U / mgprot.

\subsection{Statistical Analysis}

Two way analysis of variance was performed on all data using the General Linear Model (GLM) procedure of SPSS (SPSS 11.0), and Duncan's test was used to separate the means. A significance level was set at $P<0.05$.

\section{Results and Discussion}

\subsection{Growth Performance of Broilers}

Growth performance indexes of broilers were influenced by oil source (Table 2), BW of broilers at $42 \mathrm{~d}$ was decreased, food/gain of $0-42 \mathrm{~d}$ increased in FO group compared to $\mathrm{CO}$ group. The results are similar as An et al. (2010) and Pappas et al. (2005), who found inclusion of FO in the maternal diet reduced the weights of the eggs and the newly-hatching chicks, morover, maternal nutrition brings about an persistent effect on the progeny, Pappas et al. (2006) reported chicks hatched from hens fed FO were $11 \mathrm{~g}$ lighter than those hatched from hens fed soya oil at $14 \mathrm{~d}$ posthatch. In the present experiment, BW of chicks at $42 \mathrm{~d}$ of age in $\mathrm{FO}$ group was almost $100 \mathrm{~g}$ lighter than those in CO group, which suggests that there is an additive effect of maternal and posthatch diet on performance of broilers.

VE level also influenced broilers performance, food/gain of 0-42 d was sinificantly higher in group of $100 \mathrm{mg} / \mathrm{Kg} \mathrm{VE}$ than that in $20 \mathrm{mg} / \mathrm{Kg} \mathrm{VE}$ group, there was no significant effect of VE level on BW or food intake (FI). This phenomenon may be partly attributed to the lower egg weight and lower neonatal weight observed in the higher VE group (An et al., 2010), this result indicated that higher level of VE in maternal and posthatch diet may have a negative effect on the growth performance of the broilers. However, there was no significant interaction between oil source and VE level on broiler performance indexes.

\subsection{Antioxidant Capability in Serum of Broilers 3.2.1 Content of $M D A$}

Study results indicated that different oil source played different antioxidant effect (Table 3). MDA contents in serums of broilers at $10 \mathrm{~d}, 21 \mathrm{~d}, 28 \mathrm{~d}$ and $42 \mathrm{~d}$ were substantially increased due to the replacement of $\mathrm{CO}$ with FO in maternal and posthatch diets. This effect was consistent with our previous finding in egg yolk, and also indicated that $\mathrm{FO}$ rich in n-3 PUFA is susceptible to peroxidationF (An et al., 2010).

$100 \mathrm{mg} / \mathrm{kg}$ VE played an effective antioxidant effect, MDA concentration in serums of broilers at $21 \mathrm{~d}, 28 \mathrm{~d}$ and $42 \mathrm{~d}$ was significantly lower than that in $20 \mathrm{mg} / \mathrm{kg}$ VE group. These results were consistent with previous studies (Cherian et al., 1996; Surai, 2000).

Except for the two main effects, there was a substantial interaction $(P<0.05)$ between oil sources and vitamin levels at $28 \mathrm{~d}$, and also a trend at $42 \mathrm{~d}$, the highest MDA content of serums was always observed in FO with $20 \mathrm{mg} / \mathrm{kg} \mathrm{VE}$ group, the lowest MDA content was occured in CO with $100 \mathrm{mg} / \mathrm{kg}$ VE group.

N-3 PUFA is highly susceptible to peroxidation, which may reduce tocopherol concentration in tissues and increase the need of antioxidant protection during periods of rapid growth (Cherian and Sim, 2003), $\alpha$-tocopheryl acetate (VE), as a dietary lipophilic antioxidant, has been widely reported to be effective in protecting animal against the oxidative damage caused by free radicals. These results in the present study also remind us much more antioxidants should be applied when animal fed diets including oil rich in n-3PUFA than n-6PUFA to prevent the possible oxidative stress.

\subsubsection{Activity of Total Superoxide Dismutase (T-SOD)}

Activity of SOD is an indication of antioxidant capacity of the tissues, lipid peroxidation will be initiated when the generation of reactive oxygen species (ROS) such as $\mathrm{H}_{2} \mathrm{O}_{2}$, the hydroxyl radical, and superoxide, or other free radicals exceed the antioxidant capabilities of cells or tissue, SOD plays an important role in protecting cells from damage caused by ROS, SOD converts superoxide to $\mathrm{H}_{2} \mathrm{O}_{2}$ and oxygen In turn, $\mathrm{H}_{2} \mathrm{O}_{2}$ is reduced by Catalase (CAT) and Gluta-

Table 2. Growth performance of the progeny broilers

\begin{tabular}{|c|c|c|c|c|c|c|c|}
\hline \multirow{2}{*}{ Oil source } & \multirow{2}{*}{$\mathrm{V}$ E(mg /Kg) } & \multicolumn{3}{|c|}{0 to $21 \mathrm{~d}$} & \multicolumn{3}{|c|}{$0-42 d$} \\
\hline & & $\mathrm{FI}(\mathrm{g})$ & $\mathrm{BW}(\mathrm{g})$ & $F: G$ & $\mathrm{FI}(\mathrm{g})$ & $\mathrm{BW}(\mathrm{g})$ & $F: G$ \\
\hline $\mathrm{CO}$ & 20 & 753.46 & 542.10 & 1.49 & 2830.88 & 1757.20 & 1.65 \\
\hline $\mathrm{CO}$ & 100 & 775.17 & 582.00 & 1.43 & 2894.55 & 1741.48 & 1.70 \\
\hline FO & 20 & 743.83 & 564.44 & 1.42 & 2850.83 & 1704.50 & 1.72 \\
\hline $\mathrm{FO}$ & 100 & 755.86 & 565.00 & 1.44 & 2789.46 & 1597.10 & 1.79 \\
\hline SEM & & 7.98 & 7.81 & 0.01 & 35.52 & 22.72 & 0.01 \\
\hline \multirow[t]{2}{*}{ Oil source } & $\mathrm{CO}$ & 764.31 & 562.05 & 1.46 & 2862.72 & 1749.34 & 1.68 \\
\hline & FO & 749.85 & 564.72 & 1.43 & 2820.15 & 1650.80 & 1.76 \\
\hline \multirow[t]{3}{*}{$\mathrm{VE}$} & 20 & 748.65 & 553.27 & 1.46 & 2840.86 & 1730.85 & 1.68 \\
\hline & 100 & 765.51 & 573.50 & 1.44 & 2842.01 & 1669.29 & 1.75 \\
\hline & $P$-value & & & & & & \\
\hline Oil source & & 0.38 & 0.87 & 0.19 & 0.56 & 0.05 & 0.00 \\
\hline VE & & 0.31 & 0.21 & 0.39 & 0.99 & 0.20 & 0.01 \\
\hline Oil XVE & & 0.77 & 0.23 & 0.07 & 0.40 & 0.33 & 0.46 \\
\hline
\end{tabular}


Table 3. Content of MDA and activity of T-SOD in serum of the progeny broilers $(n=6)$

\begin{tabular}{|c|c|c|c|c|c|c|c|c|c|}
\hline \multirow{2}{*}{ Oil source } & \multirow{2}{*}{ VE } & \multicolumn{4}{|c|}{$\operatorname{MDA}(\mathrm{nmol} / \mathrm{m} l)$} & \multicolumn{4}{|c|}{$\mathrm{SOD}(\mathrm{U} / \mathrm{m} l)$} \\
\hline & & $10 \mathrm{~d}$ & $21 d$ & $28 \mathrm{~d}$ & $42 \mathrm{~d}$ & $10 \mathrm{~d}$ & $21 \mathrm{~d}$ & $28 \mathrm{~d}$ & $42 \mathrm{~d}$ \\
\hline $\mathrm{CO}$ & 20 & 3.23 & 4.29 & $2.82^{\mathrm{b}}$ & $3.78^{\mathrm{b}}$ & 98.82 & 120.95 & 153.07 & 133.45 \\
\hline $\mathrm{CO}$ & 100 & 2.78 & 3.57 & $2.88^{\mathrm{b}}$ & $3.47^{\mathrm{b}}$ & 122.39 & 93.71 & 139.19 & 120.31 \\
\hline FO & 20 & 4.74 & 7.94 & $5.70^{\mathrm{a}}$ & $8.83^{\mathrm{a}}$ & 94.50 & 87.15 & 166.11 & 122.78 \\
\hline $\mathrm{FO}$ & 100 & 4.23 & 5.89 & $3.65^{\mathrm{b}}$ & $5.25^{\mathrm{b}}$ & 117.38 & 100.35 & 167.65 & 128.76 \\
\hline SEM & & 0.20 & 0.30 & 0.22 & 0.40 & 6.31 & 6.66 & 5.62 & 6.79 \\
\hline \multirow[t]{2}{*}{ Oil source } & $\mathrm{CO}$ & 3.00 & 3.93 & 2.85 & 3.63 & 110.61 & 107.33 & 146.13 & 126.88 \\
\hline & FO & 4.48 & 6.92 & 4.68 & 7.04 & 105.94 & 93.75 & 166.88 & 125.77 \\
\hline \multirow[t]{3}{*}{ VE } & 20 & 3.98 & 6.11 & 4.26 & 6.31 & 96.66 & 104.05 & 159.59 & 128.11 \\
\hline & 100 & 3.50 & 4.73 & 3.27 & 4.37 & 119.88 & 97.03 & 153.42 & 124.54 \\
\hline & $P$-value & & & & & & & & \\
\hline Oil source & & 0.00 & 0.00 & 0.00 & 0.00 & 0.72 & 0.33 & 0.09 & 0.94 \\
\hline VE & & 0.26 & 0.04 & 0.049 & 0.03 & 0.09 & 0.61 & 0.59 & 0.80 \\
\hline Oil $\times$ VE & & 0.96 & 0.30 & 0.04 & 0.06 & 0.98 & 0.15 & 0.51 & 0.50 \\
\hline
\end{tabular}

${ }^{\mathrm{a}, \mathrm{b}}$ Means in the same column without common superscripts differ significantly $(P<0.05)$.

Table 4. Carcass and meat quality of $\mathbf{4 2 d - o l d ~ p r o g e n y ~ b r o i l e r s ~ ( \% ) ~}$

$(n=6)$

\begin{tabular}{|c|c|c|c|c|c|c|c|c|}
\hline \multirow[b]{2}{*}{ Oil source } & \multirow[b]{2}{*}{ VE } & \multicolumn{3}{|c|}{ Carcass composition } & \multicolumn{4}{|c|}{ Meat quality traits } \\
\hline & & $\begin{array}{l}\text { Breast } \\
\text { muscle }\end{array}$ & $\begin{array}{l}\text { Thigh } \\
\text { muscle }\end{array}$ & $\begin{array}{l}\text { Abdominal } \\
\text { fat }\end{array}$ & $\begin{array}{c}\mathrm{PH} \\
\text { value }\end{array}$ & $\begin{array}{l}\text { Drip } \\
\text { loss }\end{array}$ & $\begin{array}{l}\text { SOD } \\
(\mathrm{U} / \mathrm{mg})\end{array}$ & $\begin{array}{c}\text { MDA } \\
(\mathrm{nmol} / \mathrm{mg})\end{array}$ \\
\hline $\mathrm{CO}$ & 20 & 9.06 & 10.24 & 1.47 & 5.64 & 2.51 & 134.52 & 10.32 \\
\hline $\mathrm{CO}$ & 100 & 8.75 & 10.68 & 1.37 & 5.60 & 1.84 & 121.69 & 10.70 \\
\hline $\mathrm{FO}$ & 20 & 8.65 & 10.35 & 1.33 & 5.58 & 2.68 & 112.91 & 17.51 \\
\hline FO & 100 & 7.82 & 10.48 & 1.13 & 5.66 & 1.85 & 81.42 & 24.44 \\
\hline SEM & & 0.15 & 0.12 & 0.12 & 0.04 & 0.15 & 4.35 & 0.80 \\
\hline \multirow[t]{2}{*}{ Oil source } & $\mathrm{CO}$ & 8.91 & 10.46 & 1.42 & 5.62 & 2.18 & 128.11 & 10.51 \\
\hline & $\mathrm{FO}$ & 8.24 & 10.41 & 1.23 & 5.62 & 2.27 & 97.17 & 20.98 \\
\hline \multirow[t]{3}{*}{$\mathrm{VE}$} & 20 & 8.86 & 10.29 & 1.40 & 5.61 & 2.60 & 123.72 & 13.92 \\
\hline & 100 & 8.29 & 10.58 & 1.25 & 5.63 & 1.85 & 101.56 & 17.57 \\
\hline & $P$-value & & & & & & & \\
\hline Oil source & & 0.04 & 0.86 & 0.45 & 0.97 & 0.78 & 0.00 & 0.00 \\
\hline $\mathrm{VE}$ & & 0.07 & 0.28 & 0.55 & 0.85 & 0.03 & 0.03 & 0.04 \\
\hline Oil $\times$ VE & & 0.40 & 0.56 & 0.84 & 0.49 & 0.79 & 0.31 & 0.06 \\
\hline
\end{tabular}

thione peroxidase (GPx) to $\mathrm{H}_{2} \mathrm{O}$ and oxygen (Jones et al., 1981).

From Table 3, we can find that activity of T-SOD in serum of broilers was not changed by different oil sources or different VE levels, this finding was consistent with Combs (1981), who reported that GPx, CAT, or SOD activities in liver or brain were not affected in chicks fed supplemental $\mathrm{VE}(100 \mathrm{mg} / \mathrm{kg})$.

This results in our present study indicated that lipid peroxidation was prevented not mainly by mechanism of SOD activity improvement, but the higher VE level enhancement, the higher level VE may be the mainly mechanism of antioxidant defensive system in the experiment.

\subsection{Carcass and Meat Quality Traits}

Effects of diets on carcass composition and meat quality of broilers are shown in Table 4. Birds from FO group exhibited lower breast meat yield compared to $\mathrm{CO}$ group, besides, there was no obvious effect of oil source on thigh muscle or abdominal fat yield. VE level also had no clear effect on carcass composition of the broilers.

Regarding breast meat quality traits, meat MDA was significantly increased in FO group compared to CO group $(20.98 \mathrm{nmol} / \mathrm{mg}$ to $10.51 \mathrm{nmol} / \mathrm{mg})$, the reslult was in good agreement with literature data (Song et al., 2000). In addition, meat SOD activity was reduced significantly in FO group, different from that in serums (Table 3), because there was no significant effect of oil source on SOD activity of serums. The results attributed to different tissues of broilers and also partly to the cumulative effects of maternal and posthatch dietary treatment. There was no clear effect of oil source on $\mathrm{pH}$ value or drip loss of the breast meat.

However, contrary to our expectation, we observed a very interesting phenomenon happened about higher level of $\mathrm{VE}$ on breast meat quality, different from serums of the broilers, meat MDA was increased significantly, meat SOD activity was reduced significantly in $100 \mathrm{mg} / \mathrm{kg} \mathrm{VE}$ group compared 
to $20 \mathrm{mg} / \mathrm{kg}$ VE broilers, there was an interaction trend $(P=$ 0.06 ) between oil source and VE level on meat MDA, the FO group with higher VE appeared the highest MDA content in breast meast. The authors think this may be related to cumulative effect of maternal and posthatch dietary treatment. Chen et al. (1998) reported that VE had antioxidant activity at a low concentration and prooxidant activity at a high concentration (120 mg VE/kg diet) in laying hens. In our present study, progeny broilers from hens fed higher (lower) level of $\mathrm{VE}$ were still fed diets containing higher (lower) level of VE, the accumulation of long time feeding may produce an additive effect on meat antioxidant capacity, and also remind us of the possible prooxidation effect. Whether the rise of meat MDA and the decrease of meat SOD activity in broilers from higher VE was due to the prooxidant effect of higher VE for long time application need further study.

Higher level of VE significantly reduced drip loss of the breast meat. The result suggests that VE has the potential of improving water storage ability of the breast meat. Besides, there was no obvious difference of oil source or VE level on $\mathrm{pH}$ value of breast meat.

\section{Conclusion}

FO addition in maternal and posthatch diet significantly reduced body weight of broilers at $42 \mathrm{~d}$, increased food/gain of 0-42 d, significantly increased MDA content of serums and breast meat, also decreased SOD activity of breast meat compared to $\mathrm{CO}$ group. Maternal and posthatch dietary 100 $\mathrm{mg} / \mathrm{Kg}$ VE significantly decreased MDA concentration in serums of broilers, reduced drip loss of the breast meat, but the possible prooxidation to breast meat of high level VE for long time use shoud arose more attention.

\section{Acknowledgments}

This work was supported financially by the National Eleventh Five-Year Science \& Technology Program of China (Project No. 2006BAD12B07).

\section{References}

An SY, Guo YM, Ma SD, Yuan JM and Liu GZ. Effects of different oil sources and vitamin $\mathrm{E}$ in breeder diet on egg quality, hatchability and development of the neonatal offspring. AsianAustralasian Journal of Animal Sciences, 23: 234-239. 2010.

Chen JY, Latshaw ID, Lee HO and Min DB. $\alpha$-Tocopherol content and oxidative stability of egg yolk as related to dietary $\alpha$ tocopherol. Journal of Food Science, 63: 919-922. 1998.

Cherian GF and Sim JS. Maternal and posthatch dietary polyunsaturated fatty acids alter tissue tocopherol status of chicks. Poultry Science, 82: 681-686. 2003.

Cherian GF, Wolfe W and Sim JS. Dietary oils with added tocopherols. Effect on egg or tissue tocopherols, fatty acids, and oxidative stability. Poultry Science, 75: 423-431. 1996.

Combs GF and Jr. Influences of dietary vitamin E and selenium on the oxidant defense system of the chick. Poultry Science, 60: 2098-2105. 1981.
He X, Yang XJ and Guo YM. Effects of different dietary oil sources on immune function in cyclophosphamide immunosuppressed chickens. Animal Feed Science and Technology, 139: 186200. 2007.

Hulan HW, Proudfoot FG, Ackman RG and Ratnayake WMN. Omega-3 fatty acid levels and performance of broilers chickens fed redfish meal or redfish oil. Canadian Journal of Animal Science, 68: 533-547. 1988.

Jones DP, EklowL, Thor H and Orrenius S. Metabolism of hydrogen peroxide in isolated hepatocytes: relative contributions of catalase and glutathione peroxidase in decomposition of endogenously generated $\mathrm{H}_{2} \mathrm{O}_{2}$. Archives of Biochemistry and Biophysics, 210: 505-516. 1981.

Kidd MT. A treatise on chicken dam nutrition that impacts on progeny. World's Poultry Science Journal, 59: 475-494. 2003.

Kremer JM. n-3 Fatty acid supplements in rheumatoid arthritis. American Journal of Clinical Nutrition, 71: 349S-351S. 2000.

Lin YF, Tsai HL, Lee YC and Chang SJ. Maternal vitamin E supplementation affects the antioxidant capability and oxidative status of hatching chicks. Journal of Nutrition, 135: 2457-2461. 2005.

Meydani M, Natiello F, Goldin B, Free N, Woods M, Schaefer E, Blumberg JB and Gorbach SL. Effect of long-term fish oil supplementation on vitamin $\mathrm{E}$ status and lipid peroxidation in women. Journal of Nutrition, 121: 484-491. 1991.

Ministry of Agriculture of P. R. China. Feeding Standard of Chickens. Beijing, China. 2004.

Oarada M, Tsuzuki T, Gonoi T, Igarashi M, Kamei K, Nikawa T, Hirasaka K, Ogawa T, Miyazawa T, Nakagawa K and Kurita N. Effects of dietary fish oil on lipid peroxidation and serum triacylglycerol levels in psychologically stressed mice. Nutrition, 24: 67-75. 2008.

Pappas AC, Acamovic T, Sparks NHC, Surai PF and McDevitt RM. Effects of supplementing broiler breeder diets with organic selenium and polyunsaturated fatty acid on egg quality during storage. Poultry Science, 84: 865-874. 2005.

Pappas AC, Acamovic T, Sparks NHC, Surai PF and McDevitt1 RM. Effects of supplementing broiler breeder diets with organoselenium compounds and polyunsaturated fatty acids on hatchability. Poultry Science, 85: 1584-1593. 2006.

Siddiqui RA, Harvey KA and Zalog GP. Modulation of enzymatic activities by $n-3$ polyunsaturated fatty acids to support cardiovascular health. Journal of Nutritional Biochemistry, 19: 417437. 2008.

Song JH, Fujimoto K and Miyazawa T. Polyunsaturated (n-3) fatty acids susceptible to peroxidation are increased in plasma and tissue lipids of rats fed docosahexaenoic acid- containing oils. Journal of Nutrition, 130: 3028-3033. 2000.

Surai PF. Effect of selenium and vitamin E content of the maternal diet on the antioxidant system of the yolk and the developing chick. British Poultry Science, 41: 235-243. 2000.

Wang YW, Field CJ and Sim JS. Dietary polyunsaturated fatty acids alter lymphocytes unset proportion and proliferation, serum immunologlobulin G concentration, and immune tissue development in chicks. Poultry Science, 79: 174-1748. 2000.

Yang X, Zhang B, Guo Y, Jiao P and Long F. Effects of dietary lipids and Clostridium butyricum on fat deposition and meat quality of broiler chickens. Poultry Science, 89: 254-60. 2010. 